\title{
EFFECT OF CONCENTRATION AND MOLECULAR MASS OF PEO ON THE MICELLIZATION AND THERMODYNAMIC BEHAVIOUR OF CETYLTRIMETHYLAMMONIUM BROMIDE (CTAB) IN AQUEOUS PEO- CTAB MIXED SYSTEM
}

\author{
ABDUR RAUF ${ }^{1,2}$, MUSA KALEEM BALOCH ${ }^{1}$, ABBAS KHAN ${ }^{* 4}$, ZAFARULLAH KHAN AND SALMA RAUF ${ }^{3}$

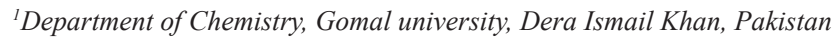 \\ ${ }^{2}$ Department of Chemistry, University of Science and Technology, Bannu, Pakistan \\ ${ }^{3}$ Department of Biological Sciences, Gomal university, Dera Ismail Khan, Pakistan \\ ${ }^{4}$ Department of Chemistry, Abdul Wali Khan University Mardan, 23200 Pakistan
}

\begin{abstract}
Polymer-surfactant mixed systems have attracted much attention due to their importance from the academic as well as applied point of view. Therefore, to evaluate the thermodynamic properties of polymer-surfactant self-assembled system, the critical micelle concentration (CMC) of CTAB and CTAB/PEO mixture was determined at different $\mathrm{CTAB} / \mathrm{PEO}$ ratios and various molecular masses of PEO by employing surface tensiometric, conductometric, and light scattering techniques. The $\mathrm{CMC}$ of $\mathrm{CTAB}$ was increased as the concentration and molecular mass of the polymer increased. Using surface tensiometry, the thermodynamics of adsorption, surface excess concentration and the minimum area occupied by surfactant molecules for different surfactant-polymer mixtures were also evaluated. $\mathrm{CMC}$, area per molecule, free energy of micellization and degree of counter ion binding were also determined. It was found that most of these parameters increased as the concentration of polymer increased, whereas the surface excess concentration was found to decrease by increasing the polymer ration in the mixed system. The hydrodynamic radius $\left(\mathrm{R}_{\mathrm{h}}\right)$ of the micelle particles calculated from dynamic light scattering technique showed a similar trend. Most of the results from different techniques support each others.
\end{abstract}

Key Words: Thermodynamics; micellization; surface tension; hydrodynamic radius; light scattering; PEO

\section{INTRODUCTION}

The interactions between the low molar mass surfactants and high molar mass polymers have gotten keen interest of the scientist from both academic and industrial point of view in the recent decades..$^{1-5}$ Surfactant and polymer mixtures are used together in many industrial processes and formulations to improve their properties and it has significantly inspired the concern of scientists in polymer/surfactant systems. ${ }^{6-17}$ However, the interactions of neutral polymers with surfactants are not well understood and needs more investigation. Moreover, different researcher have worked on polymer/ surfactant mixtures and mainly concentrated on their bulk solution properties, about which a significant information and understanding is available whereas, the interfacial properties of such mixtures are noticeably less available. ${ }^{18-19}$ In neutral polymer/surfactant mixture, hydrophobic interactions between the polymers and the surfactant chains are always present and can in some systems be the predominant interactive forces and the electrostatic interactions are much weaker. It is practical that the surfactants self-associate cooperatively and form aggregates, at a critical aggregation concentration (CAC). The CAC is generally lesser than the critical micellization concentration (CMC) of the surfactant by a factor of 1-10 in contrast to polyelectrolyte/ oppositely charged surfactant systems, which is about $100-1000 .{ }^{19-21}$ The potency of the polymers and surfactants interaction can be characterized by the CAC/CMC ratio, while the quantity gives a semi quantitative idea of the interaction. ${ }^{22}$ Surface tension has been considered to be a well established technique for weakly interacting systems and the key tool for the study of the air/solution interface and the patterns of behaviour, but no mechanism has been proposed to get quantitative information about these interactions, partly because the Gibb's equation cannot be used to determine the surface composition. Studies to be had so far concern water-soluble homo-polymers, poly (ethylene oxide) (PEO), or poly-(vinyl pyrrolidone) PVP, and surfactants such as SDS, CTAB. However, not much is known about the interactions among the homo-polymers and anionic or cationic surfactants. As it is declared before that polymer and surfactant interactions are controlled by a balance between hydrophobic and electrostatic interactions and are modulated by temperature and other parameters, which have an effect on the surface properties of either of the component of the system. The role of the above parameters in the stabilization of polymer-surfactant systems is not easy to quantify and very few information are available. ${ }^{23}$

Therefore, in order to address the lack of sufficient information and explore further the fundamental of such micro-polymer-surfactant mixed system; herein we report the detailed physicochemical investigation related to micellization, adsorption at air/water interface and thermodynamic behavior of CTAB in the presence of PEO having different molecular weight using different experimental techniques.

\section{EXPERIMENTAL}

\section{Material}

The surfactant $\mathrm{N}$-cetyle $\mathrm{N}, \mathrm{N}, \mathrm{N}$ trimethyle ammonium bromide, CTAB, and PEO having molecular mass 6,000, 12,000 and 35,000 kg/mol (denoted as $6 \mathrm{~K}, 12 \mathrm{~K}$, and $35 \mathrm{~K}$ ) were used for the present investigation. CTAB was obtained from Fluka (Buchs, Germany) whereas PEO samples were donated by Department of Physical Chemistry, University of Bayreuth, Germany which was originally obtained from Shell (Munich, Germany). All substances were of analytical-reagent quality and used without further purification. The deionized water having conductance in the range of 1.2 to $2.5 \mu \mathrm{S} / \mathrm{cm}$ was used as a solvent.

\section{Methods}

Surface Tension

The surface tension of all samples was measured using TE3 LAUDA tensiometer, supplied by LAUDA, Germany. All measurements were made sufficiently slowly so as to ensure equilibrium conditions. The measurements were made for different concentrations and at constant $\left(25^{\circ} \mathrm{C}\right)$ temperature. The tensiometer was first calibrated with a known weight provided by the supplier, and further tested for the surface tension of pure deionized water. The temperature was maintained using Ecoline Circulation Thermostat Model E $015 \mathrm{~T}$, Germany, which retained the temperature to $\pm 0.01^{\circ} \mathrm{C}$.

Conductance

The conductance of the solution of surfactant, polymer and their mixtures was determined in de-ionized water using InoLab Cond-720 conductivity meter (Buchs, Germany). The conductivity cell and the vessel used for the measurement were properly cleaned and the meter was standardized before use.

\section{Laser Light Scattering Measurement}

The micellization behavior of CTAB and CTAB/PEO in water was investigated by static and dynamic laser light scattering techniques. The measurements were made at different concentrations and molecular mass of polymer while temperature was kept constant. Before LLS measurements, all samples were filtered using a filter of $0.02 \mu \mathrm{m}$ and $0.25 \mu \mathrm{m}$ pore size for the solvent and solution, respectively. Instrument used for the purpose was DAWN EOS/ QELS supplied by Wyatt, USA, with helium-neon laser of $632.8 \mathrm{~nm}$ wavelength as light source. A cylindrical glass-made sample cell (SV) of $2 \mathrm{~cm}$ diameter was used for solutions under light scattering invistigation.

\section{RESULTS AND DISCUSSION}

\section{Surface Tension Measurement}

The results obtained from the surface tension measurements of the aqueous solutions of CTAB with and without the addition of PEO, having different molecular mass, are plotted as a function of its concentration in Figures 1-3. The 
plot of surface tension can be divided into three distinct parts. In the first part of the plot, the surface tension decreases slowly till it reaches a critical point; which is called the critical association concentration of the surfactant (CAC) in this report. Beyond $\mathrm{CAC}$, with further increase in $\mathrm{CTAB}$ concentration, the surface tension decreases sharply and finally reaches to a minimum value of surface tension which shows that CTAB gets adsorbed at the air-water interface and then the surface tension versus CTBA concentration profile becomes almost level off. This point is called critical micelle concentration $(\mathrm{CMC})$. Further increase in CTAB concentration does not significantly modify the surface tension; however, it can alter the size and shape of micelles. ${ }^{17}$, ${ }^{24-26}$ Such behaviour of surfactant can be explained on the basis of the fact that at low concentration the CTAB molecules are present in the molecular (unimers) level and coexist in equilibrium with monolayer at the air-water interface. As the concentration of solution was increased then the adsorption of surfactant at the interface also increased and thus reduction in the surface tension occurred. This phenomenon has been investigated in detail by Taylor and co-workers. ${ }^{17}$ Further addition of surfactant resulted in that more unimers of surfactant get accumulated at the air-water interface and hence the surface tension decreases significantly. ${ }^{17,24,26}$ While the surface tension of CTAB and CTAB/PEO mixture measured exhibited a similar trend and was found to decrease more as the molecular mass of the polymer added was increased. However, the difference between the surface tension of pure $\mathrm{CTAB}$ and that of CTAB/PEO mixture decreases with the increase in CTAB concentration and ultimately the surface tension of the mixture becomes higher than the surfactant alone as depicted in Figures 1-3. This represents that the interactions between the polymer and surfactant are weaker ${ }^{15,17,20}$, but the points where the interactions begin between $\mathrm{CTAB} / \mathrm{PEO}$, then the surfactant gets adsorbed over the polymer chains and hence the lowering in the surface tension is reduced or lost. Since the concentration of polymer is increased, more surfactant should be needed to adsorb or get solubilized over the polymer. Further, in order to completely saturate the polymer with surfactant, more amount of the surfactant is also needed when the molecular mass of PEO increased from $6 \mathrm{~K}$ to $35 \mathrm{~K}$. This indicates the interactions among CTAB and PEO chains. Likewise, when the polymer becomes fully saturated with surfactant, then further addition of surfactant again reduces the surface tension of polymer-surfactant mixture solution. Thus, more amount of surfactant can be accommodated by the polymer having higher molar mass and longer chain as compared to the one having low molar mass and shorter chain length.

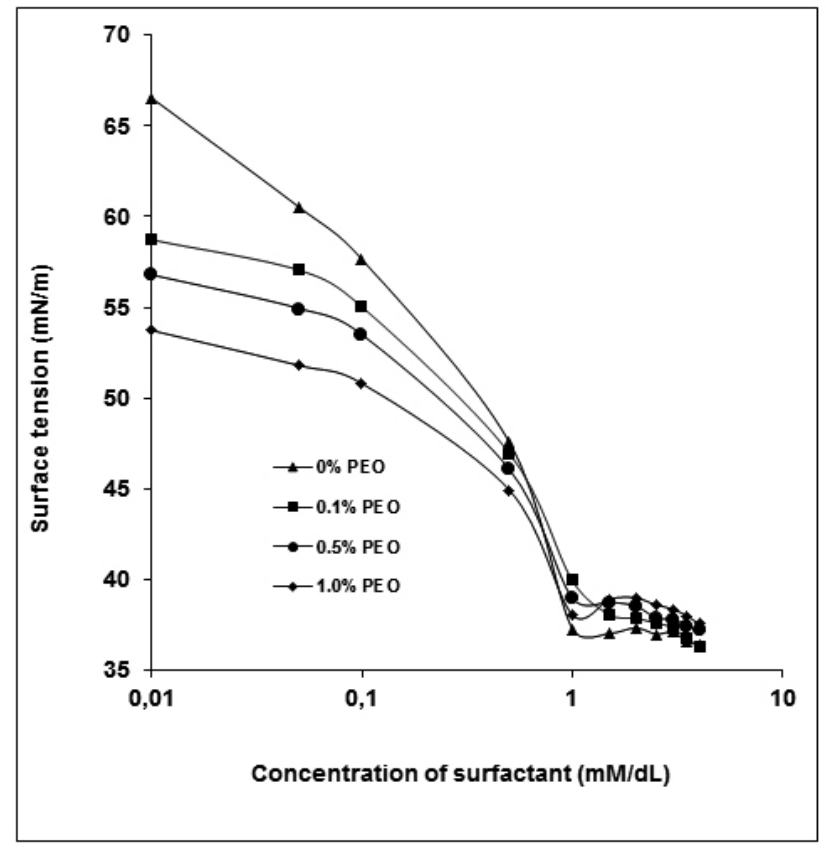

Fig. 1 Surface tension of N-cetyle N, N, N trimethyle ammonium bromide (CTAB) with and without the addition of PEO (6K).

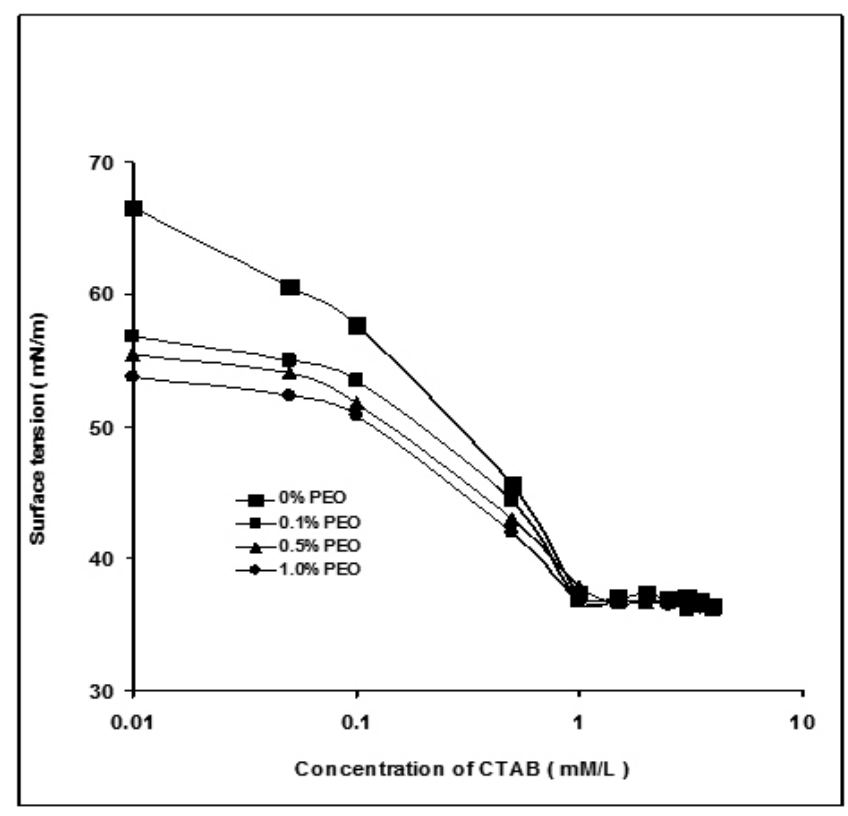

Fig. 2 Surface tension of N-cetyl N, N, N trimethyl ammonium bromide with and without the addition of PEO (12K).

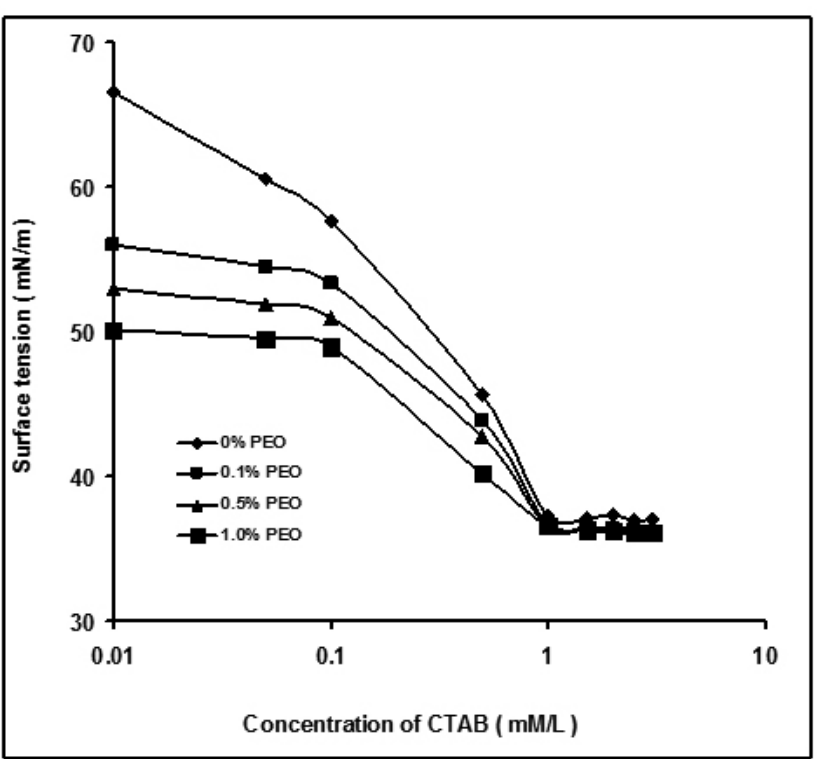

Fig. 3 Surface tension of N-cetyl N, N, N trimethyl ammonium bromide with and without the addition of PEO (35K).

The CMC calculated from the plots of surface tension versus surfactant concentration profiles (Figures 1-3) is displayed in Figure 4. It is illustrated that the $\mathrm{CMC}$ was increased with the increase in polymer concentration. This trend is according to the expectations as the surfactant gets solubilized/ adsorbed over the polymer and hence more surfactant was needed to reach $\mathrm{CMC}$ values. It was also noted that $\mathrm{CMC}$ of $\mathrm{CTAB}$ was increased with the increase in molecular mass of the polymer (Figure 4). Gharibi et al, ${ }^{31}$ Takisawa et al. ${ }^{32}$ and Gharibi ${ }^{33}$ investigated three different (SDS-PVP, SHS-PVP, and STS-PVP) systems and observed a similar trend as obtained in the present work. It is because higher is the molar mass of the polymer longer is the chain length and hence more unimers of the surfactant can be accommodated on the polymer chain compared to the polymer having low molar mass. Thus, more unimers get adsorbed at the surface of the polymer chain and consequently the less number of surfactant chains are supposed to be present in the aqueous bulk of the solution. Therefore, more amount of the surfactant is needed to get surfactant-micellized solution. 


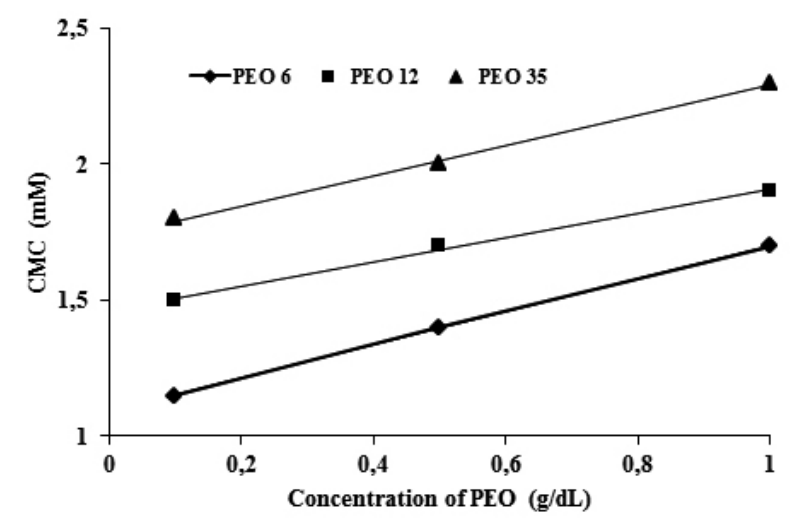

Fig. 4 Effect of molecular mass and concentration of PEO over the CMC of $\mathrm{CTAB}$ at $30^{\circ} \mathrm{C}$

From the surface tension data, the surface excess concentration $\left(\Gamma_{\min }\right)$ of surfactant in the presence of polymer PEO at CMC, the minimum area per molecule of surfactant $\left(A_{\min }\right)$ and free energy of micellization were obtained using the following relation. ${ }^{27-28}$

$$
\begin{aligned}
& \Gamma_{\min }=-\frac{1}{2.303 n R T}\left(\frac{\partial \gamma}{\partial \log C}\right)_{T} \\
& A_{\min }=\frac{10^{16}}{N_{A} \Gamma_{m}} \\
& \Delta G_{m}^{0}=(1+\alpha) R T \ln X_{c m c}
\end{aligned}
$$

Where N was Avogadro's number, $\mathrm{R}$ was gas constant, $\mathrm{T}=303 \mathrm{~K}$ and $\mathrm{n}$ was the sum of charge number of all ions resulted from the ionization of the surfactant molecule ( $\mathrm{n}=1$ for non-ionic surfactants and $\mathrm{n}=2$ or 3 for mono or divalent counter ion, respectively. Similarly $\mathrm{X}_{\mathrm{cmc}}$ is the CMC of surfactant in terms of its mole fraction in aqueous solution. Equation-1 was applied to the pre-micellar region. ${ }^{27}$ The value of $\Gamma_{\min }$ and $\mathrm{A}_{\min }$ are listed in Tables 1-3 and plotted in Figure 5. The results concluded that the longer hydrophobic tail of $\mathrm{C}_{19} \mathrm{TAB}$ is more closely packed at the air-water interface. On the other hand when polymer (PEO) was added, the $\mathrm{C}_{19} \mathrm{TAB}$ packing became loose, which suggested that $\mathrm{PEO}$ interacted strongly with $\mathrm{CTAB}$ at surface so that more polymer was adsorbed at the air water interface occupying more surface area, which was according to expectations. ${ }^{29}$

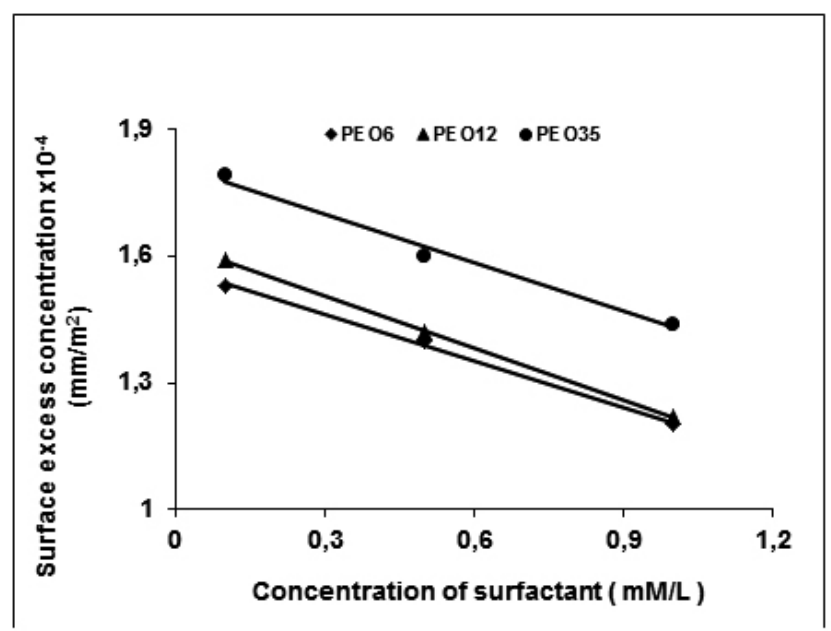

Fig. 5 Surface excess concentration of CTAB in the presence of PEO at

\section{Conductance}

The conductance of CTAB and PEO/CTAB mixtures was measured for different concentration of surfactants and in the presence of polymers having different molar masses $(6 \mathrm{~K}, 12 \mathrm{~K}$ and $35 \mathrm{~K})$. Some of the representative results are depicted in Figures 6-8. The conductance of the system was first increased sharply with the increase in surfactant concentration up to the expected CMC value. However, further increase in surfactant concentration above its CMC, the rate of increase of conductance with surfactant concentration is less prominent. Such dependence of conductance over the concentration provided an opportunity to calculate CMC from these plots (Figures 6-8). This trend was found in a good agreement with the one observed by other workers. ${ }^{20,26,30} \mathrm{Hence}$ this method was concluded to be more practicable, and in this way one can get accurate results and valuable information about the required parameters. The results obtained for $\mathrm{CMC}$ values were listed in Tables 1-3 and were consistent with the one obtained through surface tension and light scattering techniques.

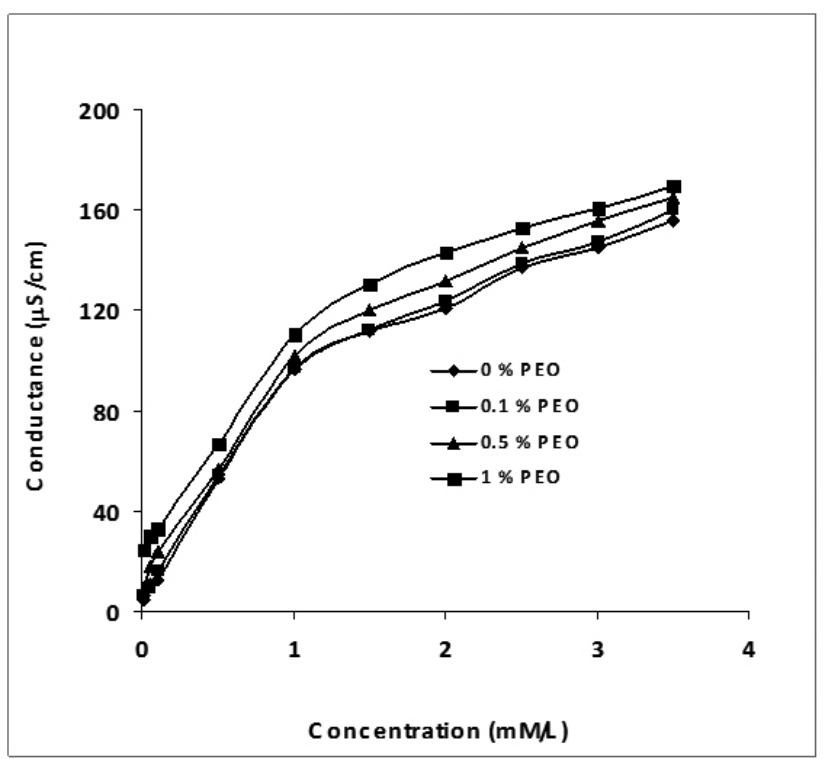

Fig. 6 Conductance of CTAB with and without the addition of PEO (6K).

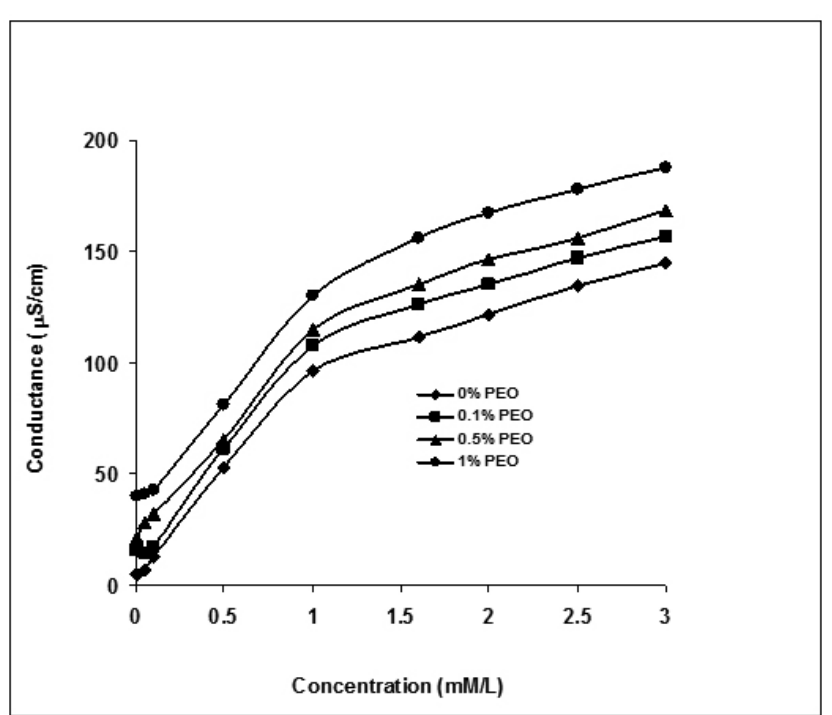

Fig. 7 Conductance of CTAB with and without the addition of PEO (12K). $30^{\circ} \mathrm{C}$. 


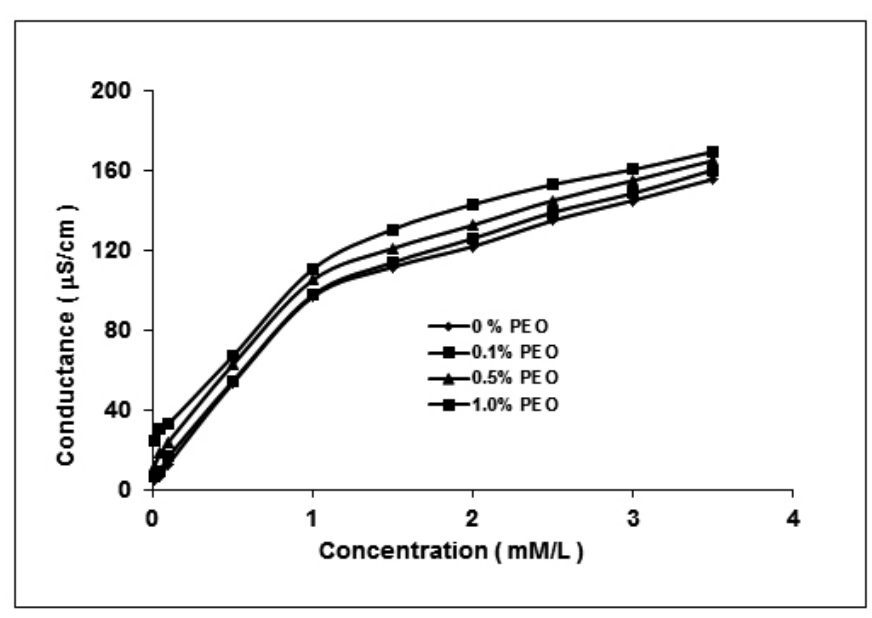

Fig. 8 Conductance of CTAB with and without the addition of PEO (35K).

Table 1. CMC, degree of counter ion binding, Free energy of micellization, surface Excess concentrations and area per molecule of CTAB in the presence of PEO (6K).

\begin{tabular}{|c|c|c|c|c|c|}
\hline $\begin{array}{c}\mathbf{P E O} \\
(\mathbf{6 K g} / \mathbf{m o l})\end{array}$ & $\begin{array}{c}\mathbf{C M C} \\
(\mathbf{m M})\end{array}$ & $\boldsymbol{\alpha}$ & $\begin{array}{c}\Delta \mathbf{G}_{\mathbf{m i c}}(\mathbf{k J} / \\
\mathbf{m o l})\end{array}$ & $\begin{array}{c}\Gamma_{\min } \mathbf{x} \mathbf{1 0} \\
\left(\mathbf{m M} / \mathbf{m}^{\mathbf{2}}\right)\end{array}$ & $\begin{array}{c}\mathbf{A}_{\min } \mathbf{x} \mathbf{1 0}^{\mathbf{5}} \\
\left(\mathbf{m}^{2}\right)\end{array}$ \\
\hline $0 \%$ & 1.12 & 0.221 & -30.4 & 1.9 & 0.874 \\
\hline $0.1 \%$ & 1.14 & 0.232 & -30.2 & 1.53 & 1.08 \\
\hline $0.5 \%$ & 1.2 & 0.237 & -29.8 & 1.44 & 1.15 \\
\hline $1 \%$ & 1.25 & 0.238 & -29.6 & 1.24 & 1.34 \\
\hline
\end{tabular}

Literature CMC value of CTAB 0.9, 1.05, 1.0mM

Estimated uncertainties for $\Delta G \pm 0.36$, for $\Gamma_{\min } \pm 0.27$ and for $A_{\min } \pm 0.19$

Table 2. CMC, degree of counter ion binding, Free energy of micellization, surface Excess concentrations and area per molecule of CTAB in the presence of PEO (12K).

\begin{tabular}{|c|c|c|c|c|c|}
\hline $\begin{array}{c}\mathbf{P E O} \\
(\mathbf{1 2} \mathbf{K g} / \mathbf{m o l})\end{array}$ & $\begin{array}{c}\mathbf{C M C} \\
(\mathbf{m M})\end{array}$ & $\alpha$ & $\begin{array}{c}\Delta \mathbf{G}_{\text {mic }} \mathbf{( k J /} / \\
\mathbf{m o l})\end{array}$ & $\begin{array}{c}\Gamma_{\min } \mathbf{4}^{4} \\
\left(\mathbf{m M} / \mathbf{m}^{2}\right)\end{array}$ & $\begin{array}{c}\mathbf{A}_{\mathbf{m i n}} \mathbf{x} \mathbf{1 0} \\
\left(\mathbf{m}^{2}\right)\end{array}$ \\
\hline $0 \%$ & 1.12 & 0.221 & $\begin{array}{c}-30.4 \pm \\
0.73\end{array}$ & 1.9 & 0.87 \\
\hline $0.10 \%$ & 1.18 & 0.241 & $\begin{array}{c}-29.86 \pm \\
0.75\end{array}$ & 1.59 & 0.104 \\
\hline 0.55 & 1.25 & 0.268 & $\begin{array}{c}-29.15 \pm \\
0.76\end{array}$ & 1.42 & 1.16 \\
\hline $1 \%$ & 1.55 & 0.301 & $\begin{array}{c}-27.68 \pm \\
0.76\end{array}$ & 1.22 & 1.36 \\
\hline
\end{tabular}

Estimated uncertainties for $\Delta G \pm 1.17$, for $\Gamma_{\min } \pm 0.28$ and for $A_{\text {min }} \pm 0.55$

Table 3. CMC, degree of counter ion binding, Free energy of micellization, surface Excess concentrations and area per molecule of CTAB in the presence of PEO $(35 \mathrm{~K})$ at $30^{\circ} \mathrm{C}$.

\begin{tabular}{|c|c|c|c|c|c|}
\hline $\begin{array}{c}\text { PEO (35Kg/ } \\
\mathbf{m o l})\end{array}$ & $\begin{array}{c}\mathbf{C M C} \\
(\mathbf{m M})\end{array}$ & $\alpha$ & $\begin{array}{c}\Delta \mathbf{G}_{\text {mic }} \\
(\mathbf{k J} / \mathbf{m o l})\end{array}$ & $\begin{array}{c}\Gamma_{\min } \mathbf{x 1 0} \\
\left(\mathbf{m M} / \mathbf{m}^{2}\right)\end{array}$ & $\begin{array}{c}\mathbf{A}_{\min } \mathbf{x} \mathbf{1 0}^{4} \\
\left(\mathbf{m}^{2}\right)\end{array}$ \\
\hline $0 \%$ & 1.12 & 0.221 & -30.4 & 1.9 & 0.87 \\
\hline $0.10 \%$ & 1.19 & 0.231 & -29.9 & 1.79 & 0.92 \\
\hline 0.55 & 1.3 & 0.236 & -29.5 & 1.6 & 1.03 \\
\hline $1 \%$ & 1.6 & 0.262 & -28.17 & 1.44 & 1.15 \\
\hline
\end{tabular}

Estimated uncertainties for $\Delta G \pm 0.95$, for $\Gamma_{\min } \pm 0.20$ and for $A_{\min } \pm 0.12$
The degree of counter-ion dissociation $(\alpha)$, a ratio of micelles charge to aggregation number, was obtained from the following relation. ${ }^{29}$

$$
\alpha=1-\beta=1-\frac{S_{2}}{S_{1}}
$$

Where $\beta$ is degree of ionization while $S_{1}=$ slope of conductivity versus concentration for the pre-micellar region and $\mathrm{S}_{2}=$ slope of conductivity versus concentration for the post-micellar region in the conductivity versus concentration plots.

The degree of counter ion binding for CTAB was obtained to be 0.221 , which was consistent with the values $(0.23-0.3)$ reported in the literature. ${ }^{29,34}$ Values of these parameters were also obtained in the presence of PEO and are listed in Tables 1-3. The addition of PEO did not alter the values as expected when PEO 35K was added which increased the values of degree of counter ion binding and rate of binding was lowered up to some extent. Free energy of micellization of CTAB in the presence of various amount of polymer were plotted in Figure 9 and tabulated in Table 1-3, which showed that the system became non-spontaneous as the concentration of polymer was increased and its degree was increased with the increase in molecular mass of polymer used. This was explained on the basis that when homo-polymer PEO having different molecular mass was added to surfactant system, the unimers of surfactant might get attached to the polymer in a string bead manner and therefore it reduced the number of surfactant molecules to form surfactant micelle and hence more surfactant was needed to reach the saturation point. ${ }^{15,26}$

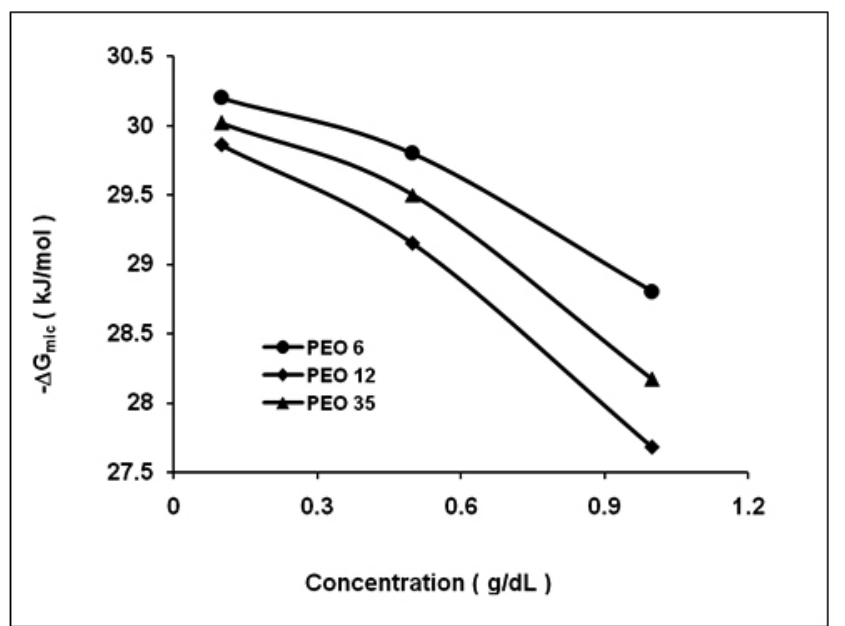

Fig. 9 Free energy of micellization of CTAB in the presence of different amount of PEO measured at $30^{\circ} \mathrm{C}$.

\section{Light Scattering Measurement}

The values of $R_{H}$ (hydrodynamic radius) determined from dynamic light scattering techniques for pure $\mathrm{CTAB}$ and $\mathrm{PEO}-\mathrm{CTAB}$ mixture having different molecular mass of PEO are plotted in Figures 10-11. The values obtained indicate that it increases steadily till the critical micelle concentration of surfactant and above the CMC the $\mathrm{R}_{\mathrm{H}}$ values increase sharply; this behaviour shows the formation of micelle. In case of CTAB-PEO mixed system, the $\mathrm{R}_{\mathrm{H}}$ values are comparatively higher. Similarly, when the concentration and/or the molecular mass of polymer is increasing, the hydrodynamic radius of mixedmicelle is further increased. However, the rate of increase in $R_{H}$ values for CTAB-PEO mixture is lower as compared to that observed in the case of pure CTAB. Figures 10-11 also show that in the presence of PEO and when the surfactant concentration is higher than CMC, the value of $\mathrm{R}_{\mathrm{H}}$ is less than that of pure CTAB. This surprising behaviour can be explained on the fact that the surfactant gets solubilized /adsorbed over the polymer and hence the micelles size decreases as compared to pure CTAB. ${ }^{35}$ Furthermore, the increase in polymer concentration and molecular mass makes the above statement more obvious which confirms the existence of interactions between polymer and surfactant molecules. Figure 10 also shows static light scattered intensity for pure CTAB showing a similar trend to that observed in DLS. This further supports the growth of micelle formation as investigated from other techniques. 


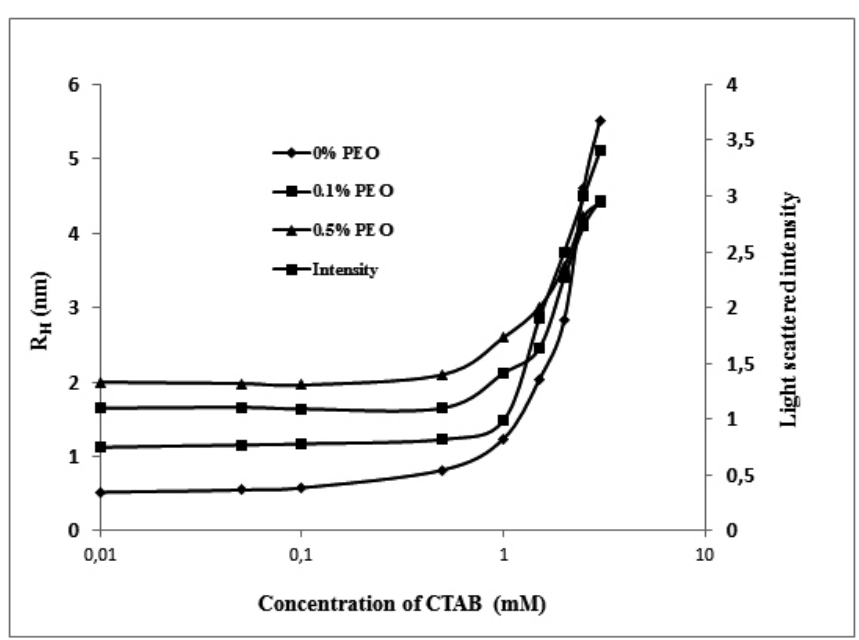

Fig. 10 Hydrodynamic radius of PEO-CTAB mixture having molecular mass $12 \mathrm{~K}$ plotted as a function of CTAB concentration.

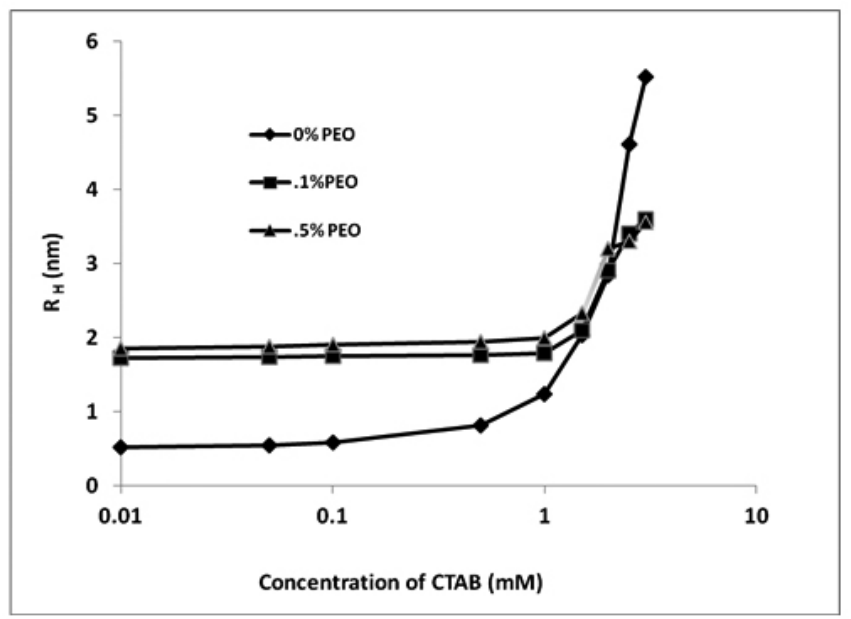

Fig. 11 Hydrodynamic radius of PEO-CTAB mixture having molecular mass $35 \mathrm{~K}$ plotted as a function of CTAB concentration.

\section{CONCLUSIONS}

The micellization behaviour of CTAB and its mixtures with PEO was studied by using different techniques in aqueous media at room temperature. From the experimental results it is concluded that $\mathrm{CMC}$ of $\mathrm{CTAB}$ was increased as the concentration and molecular mass of the polymer increased. Using surface tensiometry, the thermodynamics of adsorption, surface excess concentration and the minimum area occupied by surfactant unimers was increased as the concentration of polymer increased, whereas surface excess concentration was decreased. From the surface tension results, it can further be said that the packing of $\mathrm{C}_{19} \mathrm{TAB}$ unimers at air/water interface becomes loose in the presence of PEO. This effect is attributed to the interactions of PEO with CTAB at surface so that more polymer molecules are supposed to be adsorbed at the air /water interface; hence occupying more surface area. The hydrodynamic radius of the mixed micelle is also appreciably affected by varying the amount and molar mass of the polymer. From this detailed physicochemical investigation, it can be further concluded that there exist constructive interactions between this cationic surfactant and uncharged PEO. Thus, the type and strength of these interactions not only depend on the polymer/surfactant ratios, but also on the molecular weight of the polymer used.

\section{REFERENCES}

1. D. E. Goddard, In Interactions of Surfactants with Polymers and Proteins. Goddard. D.E.; Ananthapadmanabhan K.P.CRC Press: Boca Raton. FL, (1993).

2. M. Goswami, J. M. Borreguero, P. A. Pincus, B. G. Sumpter, Macromolecules, 48, 9050-9059 (2015)

3. D. Li, N. J. Wagner, J. Am. Chem. Soc., 135, 17547-17555 (2013)

4. U. Ashraf, O. A. Chat, M. Maswal, S. Jabeen, A. A. Dar, RSC Adv., 5, 83608-83618, (2015).

5. M. K. Baloch, A. Bano, G. Hameed, J. Chem. Soc. Pak., 24, 77-86, (2002).

6. M. Siddiq, C. Wu, M. Nawaz, M. K. Baloch, K. Mehmood, J. Chem. Soc. Pak., 23, 200-204, (2001).

7. D. Langevin, Adv. Colloid Interface Sci., 89, 467-484, (2001).

8. J. Fundin, W. Brown, Macromolecules, 27, 5024-5031, (1994).

9. R. Roe, J. Polymer. Eng. Sci., 25, 1103-1109, (2004).

10. Y. Bayrak, Turk. J. Chem., 27, 487-492, (2003).

11. P. R. Desai, N. J. Jain, R. K. Sharma, P. Bahadur, Colloids Surf. A, Physicochem. Eng. Asp., 178, 57-69, (2001).

12. M. S. Khan, Z. Ali, Chin. J. Polym. Sci., 23, 29-35, (2005).

13. N. V. Sastry, H. Hoffmann, Colloids Surf. Physicochem. Eng. Asp., 250, 247-261, (2004).

14. T. P. Lodge, Macromol. Chem. Phys., 204, 265-273, (2003).

15. E. D. Goddard, J. Colloids Interf. Sci., 256, 228-240, (2002).

16. C. L. Mesa, J. Colloids Interf. Sci., 286, 148-157, (2005).

17. D. G. F. Taylor, R. K. Thomas, J. Penfold, Adv. Colloids Interf. Sci., 132, 69-110, (2007)

18. J. Skerjanc, K. Kogej, G. Vesnaver, J. Phys. Chem., 92, 6382-6385, (1988).

19. P. M. Macdonald, D. Staring, Y. Yue, Langmuir, 9, 381-384, (1993).

20. X. Li, Z. Lin, J. Cai, L. E. Scriven, H. T. Davis, J. Phys. Chem., 99, $10865-$ 10878, (1995).

21. R. Zana, In Structure-Performance Relationships in Surfactants, 2nd ed.; Esumi, K., Ueno, M., Eds.; Marcel Dekker: New York, (2003), p. 547

22. M. Benrraou, B. Bales, R., Zana, J. Colloids Interf. Sci., 267, 519-523, (2003).

23. A. D. Aprano, C. L. Mesa, L. Persi, Langmuir, 13, 5876-5880, (1997).

24. J. Mata, T. Joshi, D. Varade, G. Ghosh, P. Bahadur, Colloids Surf. Physicochem. Eng. Asp., 247, 1-7, (2004).

25. A. Khan, G. Fatima M. Usman, W. Harrison M. Siddiq J. Chem. Soc. Pak., 31, 731-737, (2009).

26. M. K. Baloch, A. Farzana A. Rauf, G. Fatima, G. Hameed, J. Appl. Polym Sci., 116, 2133-2142, (2010).

27. M. Usman, M. A. Cheema, A. Khan, Z. H. Farooqi, V. Mosquera, M. Siddiq, J. Chil. Chem. Soc., 58, 1842-1845, ( 2013).

28. M. J. Rosen, Surfactants and interfacial phenomenon, New York, (1978).

29. O. Kosaka, P. Sehgal, H. Doe, Food Hydrocolloid., 22, 144-149, (2008).

30. M. Polverari, T.G. M. Van de Ven, J. Phys. Chem., 100, 13687-13695, (1996).

31. H. Gharibi, N. Takisawa, P. Brown, M. A. Thomson, D. M. Painter, D. M. Bloor, D. G. Hall, E. Wyn-Jones, J. Chem. Soc. Faraday Trans., 87, 707710, E. (1991)

32. N. Takisawa, D. G. Hall, E. W. Jones, P. Brown, J. Chem. Soc. Faraday Trans., 84, 3059-3070, (1988).

33. H. Gharibi, Ph.D Thesis, "Electrochemical and Kinetic Studies in Surfactant Solution", University of Salford, (1991).

34. J. M. Del Rio, C. Pombo, G. Prieto, V. Mosquera, F. Sarmiento, J. Colloids Interf. Sci., 172, 137-141, (1995).

35. W. Zhang, L. Ganzuo, M. U. Jianhai, Q. Shen, L. Zheng, H. Liang, W. Chi, Chin. Sci. Bull., 45, 1854-1857, (2000). 